\title{
Mobile augmented reality using 3D ruler in a robotic educational module to promote STEM learning
}

\author{
Nur Amira Atika Nordin, Nazatul Aini Abd Majid, Noor Faridatul Ainun Zainal \\ Faculty of Information Science and Technology, Universiti Kebangsaan Malaysia, Bangi, Selangor, Malaysia
}

\begin{tabular}{l} 
Article Info \\
\hline Article history: \\
Received Nov 30, 2019 \\
Revised Feb 14, 2020 \\
Accepted Apr 24, 2020 \\
\hline
\end{tabular}

\section{Keywords:}

Augmented reality

Dynamic

Educational games

Robotic

STEM

\begin{abstract}
Robotics education is gaining popularity among school children in line with the government desire to promote creative thinking in students through STEM based activities. However, the robots for educational games are usually made up of components and its description is usually one-way and static. Additionally, students find it difficult to visualize distances from robot movements when playing educational robotic games. Augmented reality (AR) technology is a viable tool to connect between in-context information and physical activities. The objective of this research is to design and develop an AR based application that can visualize the distance between two robots for supporting learning process in a game-based module. The application consists of three parts; the first part use AR in identification of components related to robots, while the second part involves the addition of real-time visualization in the form of AR, enabling students to learn the distance from the robot's movements. The third part used AR in providing the description of the robotic games through videos. The development of the application is based on the Agile model. The results show that the application has received positive feedbacks from students as it can increase their interest in playing robotic educational games.
\end{abstract}

This is an open access article under the CC BY-SA license.

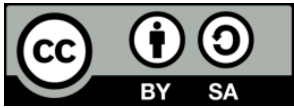

\section{Corresponding Author:}

Nazatul Aini Abd Majid,

Faculty of Information Science and Technology,

Universiti Kebangsaan Malaysia (UKM),

43600 UKM Bangi, Selangor, Malaysia.

Email: nazatulaini@ukm.edu.my

\section{INTRODUCTION}

Educational robotics is one of the area that have high potential to engage students in learning activities especially activities related to science, technology, engineering, and mathematics (STEM) education. Robotic is used in the teaching and learning process in order to promote STEM education as it can be employed to directly teach about robotics or indirectly to support multi-disciplinary topics [1]. Previously, robot have been investigated for supporting pre-school children using object recognition-based second language learning method [2], promoting active learning environment [3] and increasing the ability in computational thinking [4] which is also important for STEM education. As reported by [5], educational robot system based on STEM school teacher and specifications of STEM activities are affordable, support expandable module, emphasize on hands-on activities, focus on games and attractive. Therefore, an educational robotic module based on Arduino will be a viable option.

Arduino is a widely used open source platform for both hardware and software [6]. Its low price, high availability of sensors and transducers, ease of use and open nature make the Arduino perfect for students in active learning and collaboration. Besides, learning the basics of Arduino requires the development of several coding capabilities and the open nature of the product enhances collaborative learning. There are studies been 
carried out about who developed low cost robotic kits using the Arduino. The use of Arduino robotic kit has supported and enhanced learning motivations, such as using expensive robotics like Lego, Fisher and other robot manufacturers [7]. Furthermore, Arduino can be used to introduce programming to students, improve their attitude toward technology, develop student information processing skills and help them relate concepts to everyday life [8].

An affordable robotic kit usually consists of these components which are modules, Arduino based robots and programming editor. Programming editor, such as Scratch has been used to increase interest for STEM using educational robots [9]. Mona, an interesting mobile robot that has been developed to support both education and research has these components [10]. However, there still exist lack of robotic modules that emphasize the transformation of experience in order to create knowledge from the hands-on experience. Therefore, Kolb's experiential learning theory provides a clear mechanism for the design of teaching and learning more emphasis on construction of knowledge and skills through direct experience [11]. Kolb's experiential learning theory has been incorporated in developing an educational robotic module that not only focuses on active activities but also thinking and reflection [5, 12]. It consists of four steps; concrete experience, reflection, abstraction and active experimentation respectively [13]. These steps have been the basis for the development of 'save our robot!' and 'long pole game modules' [5, 12]. These modules not only focus on teaching robotic components and programming but also mathematics according to Malaysia's education curricula. However, the modules can be further improved by adding a connection between the physical activities using the robot prototypes with in-context theories as the robotic modules can support multi-disciplinary topics.

On the other hand, conventional learning methods are adequate for lower cognitive learning because they are not effective as experience-based learning to develop higher levels of cognitive learning [14]. In term of experiential learning, there is need for requires specific analysis and application of concepts and principles in real life or simulation problem of real life. The implementation of the learning model of experience using modules as a media to support the learning process has been investigated by [15]. This study compares the implementation of experiential learning using a module with a direct learning model on the competency of measuring instruments. The results showed that the experiential learning model has a significant effect on student learning outcomes. The learning process is carried out in four stages: questions and answers between teacher and student, module learning level, discussion and presentation stage, and measurement practice level. Increasing student learning outcomes are influenced by student active involvement to feel, see, reflect, conceptualize, and apply the knowledge directly. Similarly, the implementation of e-modules with experiential learning strategies can enhance student achievement in cognitive, psychomotor and affective abilities [16].

Augmented reality (AR) is a viable option to connect between the hands-on activities with the theories as it is capable to overlay digital contents on robot prototypes through a mobile phone screen. Since AR can be used to combine the virtual object on the world of reality as well as allows its users to interact with virtual objects [17], this technology has been used in tourism application [18], health application [19] and halal product application [20]. In education, the use of AR to support STEM topics can be found for chemistry [21, 22], biology [23], computer organization [24] and mathematics [25, 26]. AR also has been used to support educational robot applications [27], but there is need for real-time data visualization that will be based on the current state using AR to be further investigated in the area of educational robots. Hence, the objective of the present research is to design and develop an AR based app that can visualize the distance between two robots for supporting learning process in a game based module.

\section{INTERACTIVE 3D RULER APPLICATION WITH AR FOR ROBOTIC MODULE}

A 3D ruler was proposed in this study in order to provide an interactive learning. The 3D ruler can be visualized based on two specified markers in an AR environment. Unique markers as shown in Figure 1 were attached to each of the robots; Robot 1 and 2. Furthermore, it was used to visualize the distance between the two robots in order to support the calculation of a mathematics formula in a traditional game called long pole game. Long pole game is a robotic game that was developed based on the Malaysian traditional game called "galah Panjang" [28]. In this game, one robot (Robot 2) which is the defender will not allow the opponent robot (Robot 1) which is the attacker to enter the other side of the game field. The development of the mobile app in this research as shown in Figure 1 not only support the explanation of the game but can also help the players to plan their strategy based on the distance between the attacker and the defender.

The framework for implementing the $3 \mathrm{D}$ ruler is shown Figure 2. The positions of the robots are the inputs for the main process in the framework. The distance between the two robots was calculated based on the acquisition of the positions of the two robots. Similarly, based on the distance and the location of the two robots, an image for 3D ruler was overlaid between the two robots. 


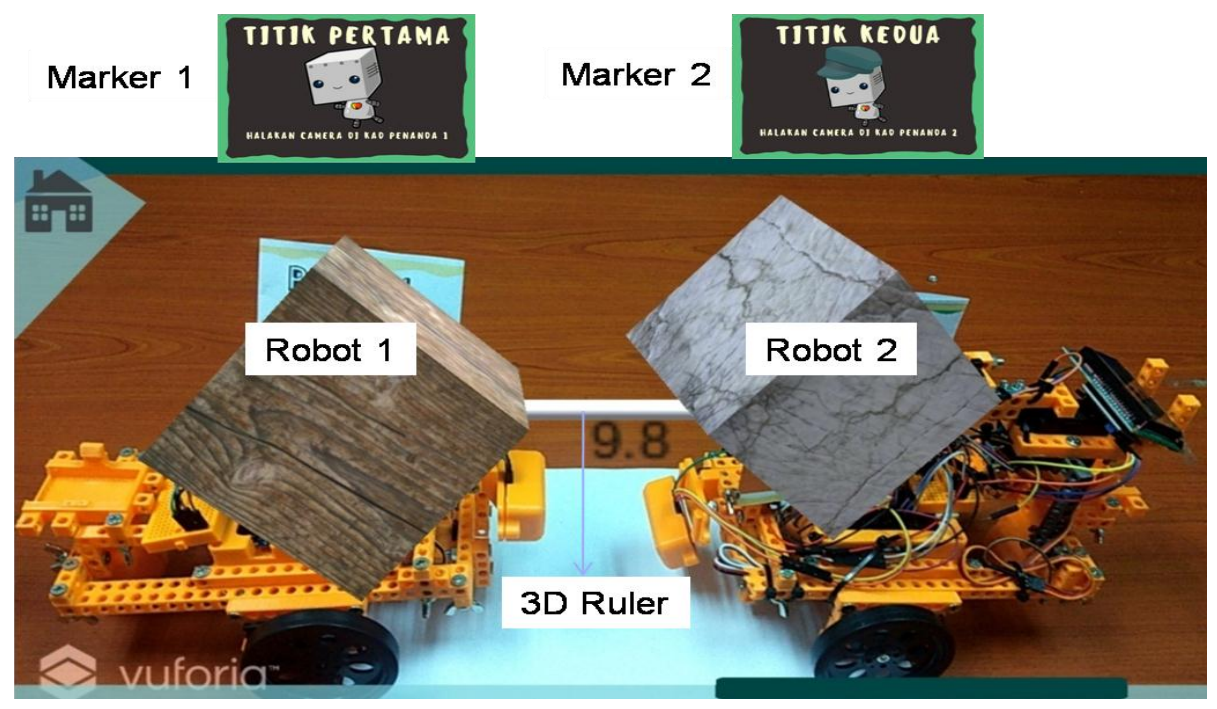

Figure 1. Visualizing the distance using 3D ruler between two robots based on AR multi target inputs

\begin{tabular}{|c|c|c|c|c|}
\hline & Input & Process & & Output \\
\hline $\begin{array}{l}\text { Robot } 1 \\
\text { (Attacker) }\end{array}$ & Position 1 & $\begin{array}{l}\text { Calculate the } \\
\text { distance between }\end{array}$ & Distance & $\begin{array}{l}\text { Visualize the distance } \\
\text { using } 3 D \text { ruler overlay }\end{array}$ \\
\hline $\begin{array}{c}\text { Robot } 2 \\
\text { (Defender) }\end{array}$ & Position 2 & $\begin{array}{c}2 \text { based on markers } \\
\text { tracking }\end{array}$ & & $\begin{array}{l}\text { Detween Robot } 1 \text { and } \\
\text { Robot } 2\end{array}$ \\
\hline
\end{tabular}

Figure 2. The calculation of 3D ruler for distance visualization

The algorithm for the visualization of the 3D ruler is given below:

1) Get position for Robot 1 from its marker: $X$

2) Get position for Robot 2 from its marker: Y

3) Calculate the distance between Robot 1 and Robot 2: distance $=Y-X$

4) Get the link position between Robot 1 and Robot 2: Z

5) Calculate the new position of the 3D ruler: $\mathrm{Z}+$ distance/2

6) Visualize the 3D ruler

From the above algorithm; Step 1 until Step 6 will be implemented using AR environment. The position of the robot will be tracked by the AR engine via the phone camera based on the attached marker. Users can see the image of the 3D ruler overlaid on top of the mobile phone screen when there is a change in the distance. The visualization of the 3D ruler will be updated based on the changing positions of both Robot 1 and Robot 2 so that the users can see the real time value while playing the game.

\section{RESEARCH METHOD}

\subsection{Participants}

The participants of the present study were four secondary school students and seven higher education students. The first four students aged between 13-15 years old, while that of the students from the higher education aged between 19-22 years old.

\subsection{Mobile Application}

The mobile application that was developed and used in the present study is called ARLongPole game, in which the 3D ruler algorithm makes one of the main functions. Overall, has three functions as shown in Figure 3, which are; video-based AR for games explanation (VideoAR), 3D model using AR for robotic component visualization (RobotAR), and 3D ruler using AR for visualizing the distance between two robots in a long pole game (JarakAR). The first function, VideoAR consists of two videos about robotic component and the game that will be played based on the selected marker. The second function, RobotAR

Mobile augmented reality using $3 D$ ruler in a robotic educational module to... (Nur Amira Atika Nordin) 
consists of three 3D models, which are; Arduino, servo motor and sensor that will be visualised based on the selected marker. The third function, JarakAR consists of the visualization of a 3D ruler as discussed in section 2.0 .

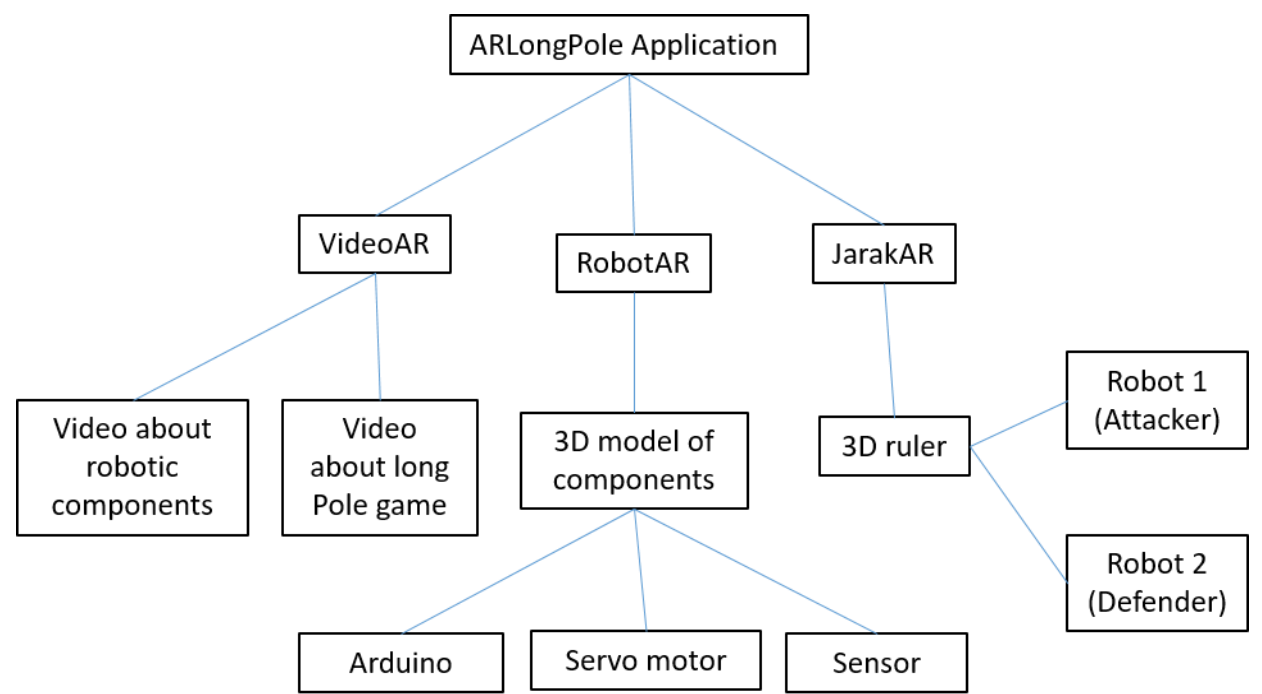

Figure 3. The main functions in the mobile application: RobotAR, VideoAR and JarakAR

The mobile app was developed based on rapid application development (RAD), which consists of four main phases: planning, design, development and implementation. In order to integrate $A R$ in the mobile app, the development of the mobile app involves: (1) Unity 3D for Android platform development using C\#, (2) Vuforia for augmented reality development, and (3) Blender for 3D editing. The main menu of the application consists of the three main functions, which are; RobotAR, VideoAR and JarakAR as shown in Figure 4.

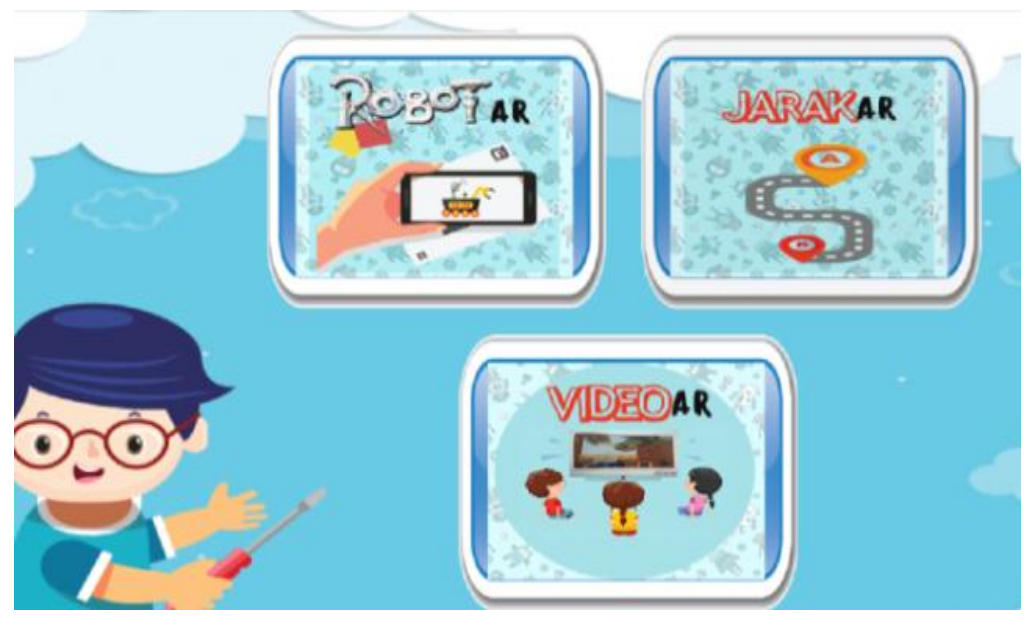

Figure 4. Three modules in the ARLongPole application

In order to support self-learning, the students can select RobotAR button for visualizing the 3D model of the robotic components, illustrated in Figure 5. The students can proceed to select VideoAR button for tracking the specified marker so that they can learn more about the game based on the overlaid video on the mobile phone screen, illustrated in Figure 6. This function is important in the development of a mobile application that support robotic module. This is because the robotic module consists of assembling of the robot components and developing the programs for the robots. 


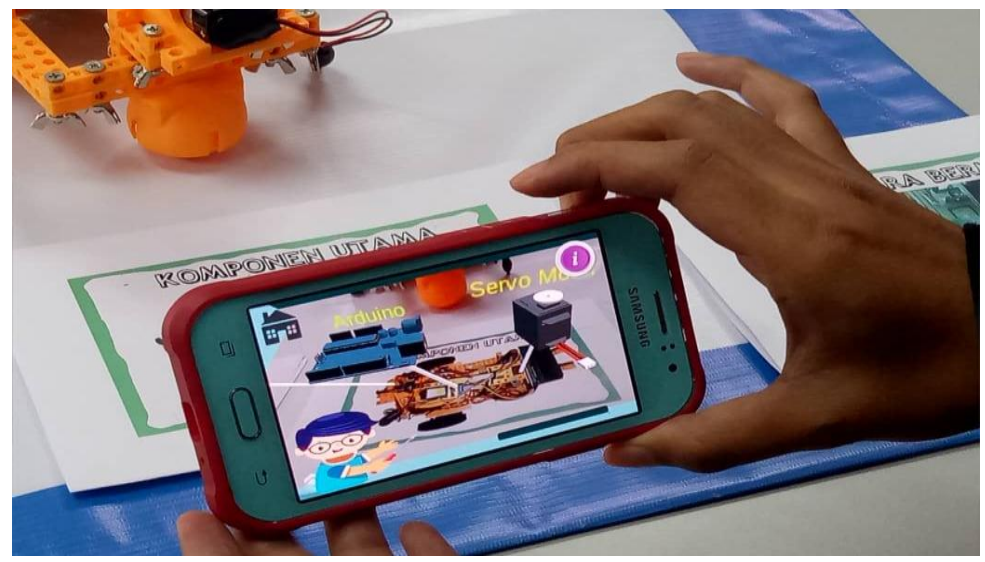

Figure 5. Learning robotic components module based on AR

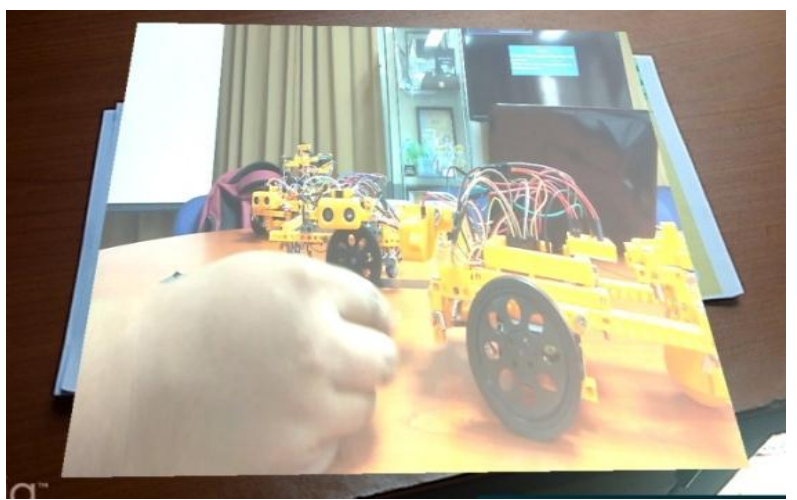

Figure 6. Video for explaining long pole game

After watching the video, the students can start to play the long pole game. They can modify the programs for the robots via a visual programming editor called blockly. In order to see the output of the programs, the robots will be located on a printed canvas as shown in Figure 7. While playing the game, the players can start to use the third function which is JarakAR in order to visualize the real-time changes of the robots' distance. The 3D ruler will be updated based on the location of the robots. The distance can be further used by the player to calculate the speed of the robot.

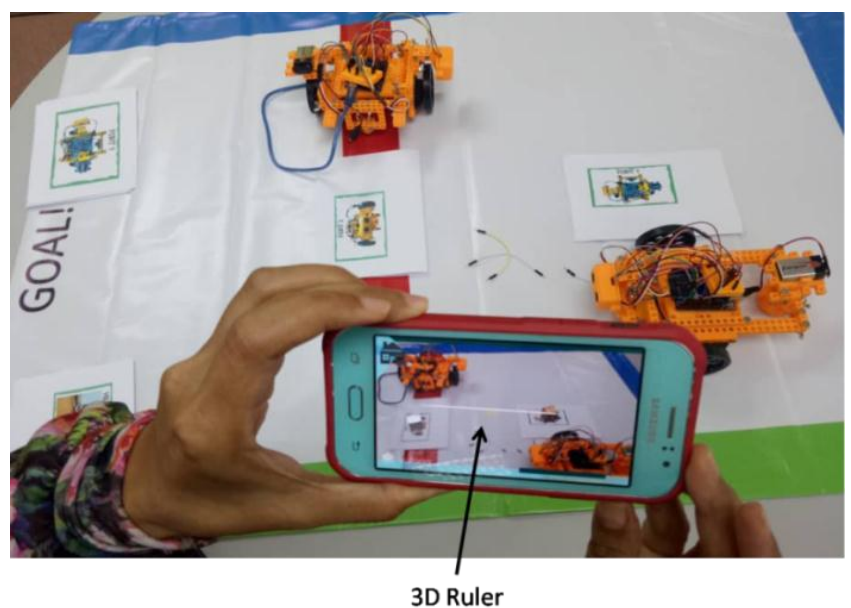

Figure 7. The visualization of the 3D ruler in supporting the educational games in real time 


\section{RESULTS AND DISCUSSION}

Data was collected through distributed questionnaires and observations made while respondents use this application. Descriptive statistical analysis was carried out to identify the satisfaction level of using the developed AR application in learning materials related to robotic modules. The mean and the frequency, scale of 4 to 5 , were calculated to identify the level of students' interest and engagement in using the application. It can be seen from Table 1 that item 7 and 12 has the highest level of engagement with mean 4.5 and frequency 11. The overall mean for each of the attributes are in the range of 3.9 to 4.5. This indicates that the respondents were satisfied with the use of the AR based application in learning an educational robotic game. As shown in Figure 8, two students were engaged with the app in learning the educational game.

Table 1. Frequency (scale of 4 to 5) for the interest and engagement of using mobile apps AR

\begin{tabular}{llll}
\hline Num. & Item & Frequency & Mean \\
\hline 1 & This application is very easy to use & 9 & 4.25 \\
2 & The content of the application is compelling & 8 & 4.2 \\
3 & I can visualize distances from robot movements & 10 & 4.3 \\
4 & I found this app to have an interesting interface & 8 & 3.9 \\
5 & This app enhances my understanding of the main components of the robot & 10 & 4.1 \\
6 & I was able to identify the main components of the robot through this application & 10 & 4.4 \\
7 & I feel like I can understand how to play Long games using robot & 11 & 4.5 \\
8 & This app has increased my interest in learning robotics & 10 & 4.2 \\
9 & This app encourages me to learn interactively & 9 & 4.4 \\
10 & This application enhances my interest in Technology & 9 & 4.1 \\
11 & This app interests me in the field of Math through distance visualization & 8 & 4.1 \\
12 & This app enhances the curiosity of developing robots & 11 & 4.5 \\
\hline
\end{tabular}

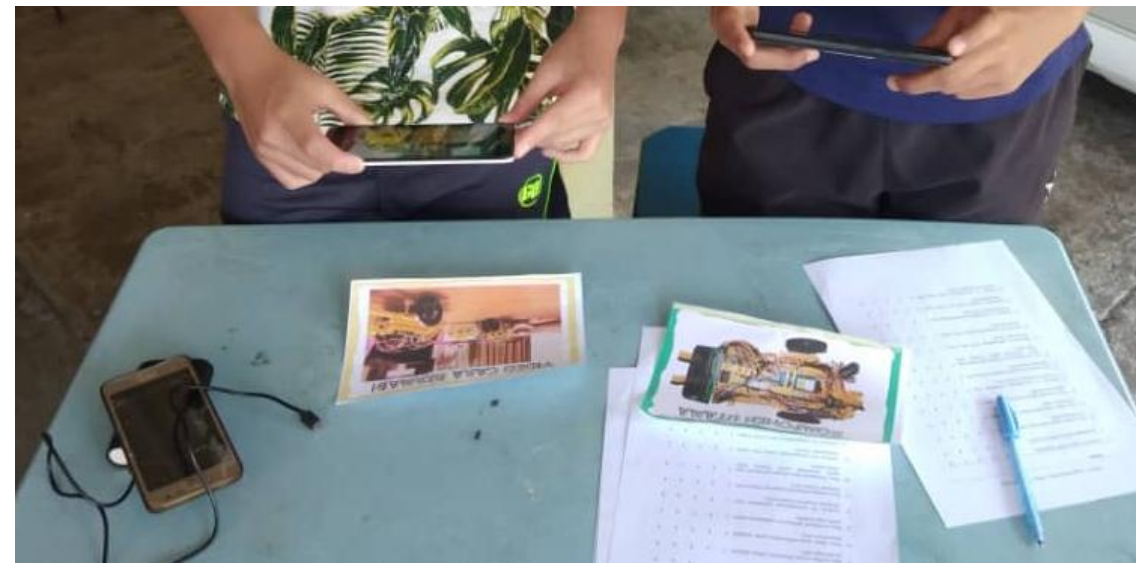

Figure 8. Two students were using the app in learning the educational robotic game

Respondents also show positive response in using 3D ruler for visualizing the distance between robots as some respondents stated:

"I like using AR for visualizing the distance because it is easy to know the distance virtually"

"I like the 3D ruler part because it solved the difficulty in estimating the distance between objects"

An interview was conducted with an expert in educational robotic, and the expert responded positively during the usage of the application. The distance visualization module embedded in the learning module for the games using robots was said to be interesting and can help students visualize distances in real time. The main feature of the ARLongPole games application is the function of the 3D ruler. By visualizing the distance via using the ruler, as shown in Figure 7, students can further relate the distance of the robot with the strategy to move the robot in order to win the game. The expert also said that the concept of the robot component description using the AR concept made it easier for students to know the main components of a robot. This is because this robot-related lesson requires students to have a strong interest in learning it. As the use of AR technology can make learning more fun. Hence, the expert felt that the application could help students understand how to play long games with robots and learn robot components as well. The use of this app to play the robot is expected to make students more self-reliant and increase their interest as AR has proven to be effective for teaching robotic modules $[29,30]$. In the future, multi modal input, such as the use of speech input in an AR application [31] can be further investigated for an effective robotic module. 


\section{CONCLUSION}

In order to engage students in learning STEM using educational robotic games, the present research proposed a mobile AR application with an interactive 3D ruler. The $3 \mathrm{D}$ ruler will be overlayed on the mobile phone screen in order to show the real-time distance between the two robots. Based on the value indicated on the screen, the students can relate topics in school, such as distance while playing. This mobile AR application was designed to help students to get in-context information while playing the robotic educational game. The students can retrieve the information by tracking markers related to the robotic components and robotic games. Also, they can visualize the distance between two robots by using real-time value through 3D ruler technique. This will enhance their understanding about the learning environment, especially for those who are new in using robotic components. In order to promote STEM among students, the proposed mobile application can be a supportive tool to connect between the theories and physical activities. In addition, this mobile application comes with a low-cost robot so that it is accessible to a wide range of students worldwide. Therefore, these efforts will support the government's aim to expand access to quality and capability education.

\section{ACKNOWLEDGEMENTS}

This work was supported by the Ministry of Higher Education of Malaysia and Universiti Kebangsaan Malaysia (FRGS/1/2017/ICT04/UKM/1).

\section{REFERENCES}

[1] M. Garduño-Aparicio, J. Rodríguez-Reséndiz, G. Macias-Bobadilla, and S. Thenozhi, "A multidisciplinary industrial robot approach for teaching mechatronics-related courses," IEEE Transactions on Education, vol. 61, no. 1, pp. 55-62, Feb. 2018

[2] Q. Wu, S. Wang, J. Cao, B. He, C. Yu, and J. Zheng, "Object recognition-based second language learning educational robot system for Chinese preschool children," IEEE Access, vol. 7, pp. 7301-7312, 2019.

[3] W. S. Burleson, D. B. Harlow, K. J. Nilsen, K. Perlin, N. Freed, C. N. Jensen, B. Lahey, P. Lu, and K. Muldner, "Active learning environments with robotic tangibles: Children's physical and virtual spatial programming experiences," IEEE Transactions on Learning Technologies, vol. 11, no. 1, pp. 96-106, 2018.

[4] K. Karaahmetoglu and O. Korkmaz, "The effect of project-based arduino educational robot applications on students' computational thinking skills and their perception of Basic Stem skill levels," Participatory Educational Research, vol. 6, no. 2, pp. 1-14, Dec. 2019.

[5] N. F. A. Zainal, R. Din, M. F. Nasrudin, S. Abdullah, A. H. Abd Rahman, S. N. H. S. Abdullah, K. A. Z. Ariffin, S. M. Jaafar, and N. A. Abd Majid, "Robotic prototype and module specification for increasing the interest of Malaysian students in STEM education," International Journal of Engineering \& Technology, vol. 7, no.3, pp. 286-290, Aug. 2018.

[6] G. Organtini, "Arduino as a tool for physics experiments," Journal of Physics: Conference Series, vol. 1076, no. 1, pp. 012026-1-7, 2018.

[7] L. A Junior, O.T Neto, M. F Hernandez, P. S. Martins, L. L. Roger, and F. A. Guerra, "A low-cost and simple arduino-based educational robotics kit," Journal of Selected Areas in Robotics and Control (JSRC), vol. 3, no. 12, pp. 1-7, 2013.

[8] N. K. Cakir and G. Guven, "Arduino-Assisted robotic and coding applications in science teaching: Pulsimeter activity in compliance with the 5E learning model," Science Activities, vol. 56 no. 2, pp. 42-51, 2019.

[9] P. Plaza, E. Sancristobal, G. Carro, M. Blazquez, F. García-Loro, M. Muñoz, M. J. Albert, B. Moriñigo, and M. Castro, "Scratch as driver to foster interests for STEM and educational robotics," IEEE Revista Iberoamericana de Tecnologias del Aprendizaje, vol. 14, no. 4, pp. 117-126, Nov. 2019.

[10] F. Arvin, J. Espinosa, B. Bird, A. West, S. Watson, and B. Lennox, "Mona: an affordable open-source mobile robot for education and research," Journal of Intelligent and Robotic Systems: Theory and Applications, vol. 94, pp. 761-775, 2019.

[11] M. K. Smith, “ David A. Kolb on experiential learning," Encyclopedia of Informal Education, [Online]. Available at: https://infed.org/mobi/david-a-kolb-on-experiential-learning/

[12] N. F. A. Zainal, R. Din, N. A. Abd Majid, M. F. Nasrudin, and A. H. Abd Rahman, "Primary and secondary school students perspective on Kolb-based STEM module and robotic prototype," International Journal on Advanced Science, Engineering and Information Technology, vol. 8, no. 4-2, pp. 1394-1401, 2018.

[13] D. A. Kolb, "Experiential learning: Experience as the source of learning and development-vol. 1," Englewood Cliffs, NJ: Prentice-Hall, 1984

[14] G. M. Warnick, J. Schmidt, and A. E. Bowden, "An experiential learning approach to develop leadership competencies in engineering and technology students an experiential learning approach to develop leadership," 121 st ASEE Annual Conference \& Exposition, 2014.

[15] A. J. Purnomo, Karsono, and A. Suharmanto, "Application of module experiential learning learning models in competence using measuring tools," in Bahasa, "Penerapan model pembelajaran experiential learning berbantuan modul pada kompetensi mengunakan alat-alat ukur (measuring tools)," Journal of Mechanical Engineering Learning, vol. 2, no. 2, 2013. 
[16] S. Sutirman, M. Muhyadi, and H. D. Surjono, "Integration of strategy experiential learning in E-module of electronic records management," Jurnal Pendidikan Vokasi, vol. 7, no. 3, pp. 275-287, 2017.

[17] R. T. Azuma, “A survey of augmented reality,” Teleoperators and Virtual Environ., vol. 6, no. 4, pp. 355-385, 1997.

[18] I. Tahyudin and D. I. S. Saputra, "A response analysis of mobile augmented reality application for tourism objects," International Journal of Electrical and Computer Engineering, vol. 7, no. 6, pp. 3500-3506, 2017.

[19] K. J. Carlson and D. J. Gagnon, "Augmented reality integrated simulation education in health care," Clinical Simulation in Nursing, vol. 12, no. 4, pp. 123-127, 2016.

[20] H. Arshad, S. A. A. Shukri, W. K. Obeidy, R. Zainal Abidin, "An interactive application for halal products identification based on augmented reality," International Journal on Advanced Science, Engineering and Information Technology, vol. 7, no.1, pp. 139-145, 2017.

[21] A. Setiawan, S. Rostianingsih, and T. R. Widodo, "Augmented reality application for chemical bonding based on android," International Journal of Electrical and Computer Engineering, vol. 9, no. 1, pp. 445-451, 2019.

[22] N. A. Abd Majid and N. Abd Majid, "Augmented reality to promote guided discovery learning for STEM learning," Int. J. on Advanced Science, Engineering and Information Technology, vol. 8, no 4-2, pp. 1494-1500, 2018.

[23] N. H. Adnan, “An interactive mobile augmented reality textbook for learning biology," Journal of Advanced Research in Dynamical and Control Systems, no. 2 SI, pp. 1719-1725, 2018.

[24] N. A. Abd Majid, H. Mohammed, and R. Sulaiman, "Students' perception of mobile augmented reality applications in learning computer organization," Procedia-Social and Behavioral Sciences, vol. 176, pp. 111-116, 2015.

[25] R. Andrea, S. Lailiyah, F. Agus, and R. Ramadiani, "Magic Boosed" an elementary school geometry textbook with marker-based augmented reality," TELKOMNIKA Telecommunication, Computing, Electronics and Control, vol. 17, no 3, pp. 1242-1249, 2019.

[26] I. Radu, B. McCarthy, and Y. Kao, "Discovering educational augmented reality math applications by prototyping with elementary-school teachers," 2016 IEEE Virtual Reality (VR), pp. 271-272, 2016.

[27] M. Albayrak, V. Altıntaş, A. M. Sümen, and G. Şener, "Robotics education based on augmented reality in primary schools,"3rd International Conference on Advanced Technology \& Sciences, Sept. 2016.

[28] N. F. A. Zainal, N. A. Abd Majid, R. Din, M. F. Nasrudin, S. Abdullah, A. H. Abd Rahman, S. N. H. S. Abdullah, K. A. Z. Ariffin, and S. M. Jaafar, "Long pole game: The integration of visual programming and robotics in learning programming," International University Carnival on E-Learning (IUCEL 2018), 2018.

[29] S. M. AlNajdi, M. Q. Alrashidi, and K. S. Almohamadi, "The effectiveness of using augmented reality (AR) on assembling and exploring educational mobile robot in pedagogical virtual machine (PVM)," Interactive Learning Environments, pp. 1-27, 2018.

[30] M. Hernández-Ordoñez, M. A. Nuño-Maganda, C. A. Calles-Arriaga, O. Montaño-Rivas, and K. E. B. Hernández, "An education application for teaching robot arm manipulator concepts using augmented reality," Mobile Information Systems, vol. 2018, no. 4, pp. 1-8, 2018.

[31] N. C. Hashim, N. A. Abd Majid, H. Arshad, and W. K. Obeidy, "User satisfaction for an augmented reality application to support productive vocabulary using speech recognition," Advances in Multimedia, vol. 2018, no. 2, pp. 1-10, 2018.

\section{BIOGRAPHIES OF AUTHORS}

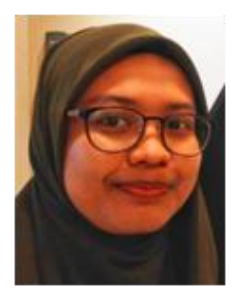

Nur Amira Atika Nordin is currently pursuing the Bachelor of Software Engineering with Honours (Multimedia System Development) at Faculty of Information Science and Technology, Universiti Kebangsaan Malaysia

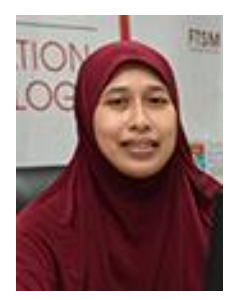

Nazatul Aini Abd Majid did her Bachelor of Computer Science with Honours and MSc (Computer Science) at Universiti Kebangsaan Malaysia and received her $\mathrm{PhD}$ from The University of Auckland, New Zealand in 2011. Currently she is a senior lecturer and researcher at the Universiti Kebangsaan Malaysia. She is a member of the Center for Artificial Intelligence Technology. Her research interest includes Augmented Reality, Educational Robotic, Multivariable Statistical Process Monitoring, Industrial Computing, High Performance Computing and Cloud Computing.

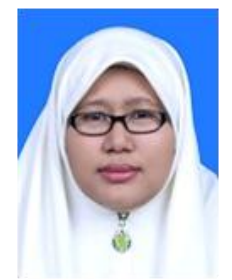

Noor Faridatul Ainun Zainal did her Bachelor of System Management and Science and MSc (System Management and Science) at Universiti Kebangsaan Malaysia. She is currently pursuing the EDD in Universiti Kebangsaan Malaysia. Currently she is an IT instructor at Faculty of Information Science and Technology, Universiti Kebangsaan Malaysia 